\title{
As linguagens expressivas e a Pesquisa Narrativa (auto)biográfica: contribuições para a formação docente dos professores e professoras da educação infantil
}

\author{
Expressive Languages and Narrative (Auto)Biographical Research: \\ Contribuitions to the Teacher Education of Early \\ Childhood Teachers
}

\section{Lenguajes expresivos e investigación (auto)biográfico-narrativa: contribuciones a la formación de maestros de la educación infantil}

Penha Mabel Farias do Nascimentol https://orcid.org/0000-0002-95I8-55I6

Eda Maria de Oliveira Henriques² https//orcid.org/0000-0002-7240-5520

Resumo: O trabalho traz relato de uma pesquisa de doutorado em andamento desde 2017 e discute os diálogos possíveis entre as linguagens expressivas ou poéticas (a arte e o brincar) com a Pesquisa Narrativa (auto)biográfica como pressupostos teóricos e metodológicos fundamentais para o processo de formação, continuada ou em serviço, de professoras e professores na educação infantil de uma rede municipal de educação, considerando, nesse contexto, a dimensão estética. Posteriormente, além de descrever os procedimentos metodológicos realizados, apresentamos algumas narrativas docentes e nossas primeiras reflexões sobre a relação entre formação (autoformação, narrativas e experiências estéticas) e suas repercussões no trabalho pedagógico desenvolvido pelos professores e professoras.

Palavras-chave: Formação docente. Dimensão estética. Pesquisa Narrativa.

Abstract: The work brings an account of a doctoral research, in progress since 2017, and discusses the possible dialogues between expressive or poetic languages (art and play) with narrative (auto)biographical research as theoretical and methodological assumptions fundamental to the process training, continuing or in service, of teachers in early childhood education in a municipal education network. In this context, the importance of the aesthetic dimension in the training process is highlighted. As part of the set of methodological procedures carried out, some teaching narratives were reported and the first reflections on the relationship between formation,

\footnotetext{
I Mestre em Educação Pela Universidade Federal Fluminense/UFF. Pedagoga da Unidade de Educação Infantil da Rede Municipal de Educação de Niterói. E-mail: penhamabel@gmail.com

2 Professora Associada da Faculdade e do Programa de Pós-graduação em Educação da Universidade Federal Fluminense/UFF.
}

Olhar de professor, Ponta Grossa, v. 24, p. I-18, e-17624.080, 2021.

Disponível em <https://revistas2.uepg.br/index.php/olhardeprofessor> 
self-formation, narratives and aesthetic experiences and their repercussions on the pedagogical work developed by teachers and teachers were constructed.

Keywords: Teacher Training. Aesthetic Dimension. Narrative Research.

Resumen: Este trabajo presenta una investigación de doctorado, en progreso desde 2017, y analiza los posibles diálogos entre lenguajes expresivos o poeticos (arte y juego), o sea, la dimensión estética, y la investigación (auto)biográfico-narrativa como supuestos teóricos y metodológicos en el proceso de formación docente contínua o en servicio de maestros de la educación infantil temprana de una red de educación municipal. Posteriormente, además de describir los procedimientos metodológicos realizados, presentamos algunas narrativas de los maestros y nuestras primeras reflexiones sobre la formación docente (autoformación, narrativas y experiencias estéticas) y sus repercusiones en el trabajo pedagógico desarrollado por estos maestros.

Palabras-clave: Formación de profesores. Dimensión estética. Investigación narrativa.

\section{Primeiras palavras...}

"A ideia de nós, os humanos, nos descolarmos da terra, vivendo numa abstração civilizatória, é absurda. Ela suprime a diversidade, nega a pluralidade das formas de vida, de existência e de hábitos. Oferece o mesmo cardápio, o mesmo figurino e, se possível, a mesma língua para todo mundo" Ailton Krenak

O diálogo entre as linguagens expressivas - a arte e o brincar, perpassadas pela dimensão estética, no contexto da formação dos professores e professoras da educação infantil, e a Pesquisa Narrativa (auto)biográfica - orienta este artigo. Nesse sentido, ele traz, ao mesmo tempo, os pressupostos teóricos e metodológicos da pesquisa e um breve relato dela. Assim, este trabalho ${ }^{3}$ se relaciona com uma pesquisa de doutorado ${ }^{4} \mathrm{em}$ andamento que tem como objetivo geral refletir e discutir sobre a importância das diferentes linguagens expressivas no processo de formação continuada e em serviço dos professores(as) de educação infantil e suas repercussões no trabalho docente. Iniciamos, dessa forma, trazendo primeiramente os pilares básicos da Pesquisa Narrativa (auto)biográfica e como o seu caráter de pesquisa e formação se configura neste cenário. Posteriormente, apresentamos os diálogos possíveis entre a importância das linguagens expressivas ou poéticas para o processo de formação e as narrativas de professoras de educação infantil como pressupostos fundamentais para o exercício da docência com crianças pequenas considerando a importância da dimensão estética nessa formação.

\section{A Pesquisa Narrativa (auto)biográfica e a concepção de pesquisa-formação}

Ao pensar a formação de professores e a ação pedagógica, é essencial escutar, ter um olhar sensível que favoreça a compreensão do fenômeno educativo materializado também na pessoa que é

\footnotetext{
3 Financiada pela CAPES.

${ }^{4}$ Orientada Pela professora Dra Eda Maria de Oliveira Henriques
}

Olhar de professor, Ponta Grossa, v. 24, p. I-18, e-17624.080, 2021.

Disponível em <https://revistas2.uepg.br/index.php/olhardeprofessor> 
o educador. Para entender essa junção intrincada, a pessoa e o professor ou a vida e a docência como faces da mesma moeda, relação indivisível, nos perguntamos: "por que é que fazemos o que fazemos na sala de aula"? (NÓVOA, 1995, p. 16). E para além da sala de aula, nos diferentes espaços/tempos formativos, como compreender as tramas de histórias de vida e de formação (inicial e no exercício da função) que orientam as escolhas docentes que liberam, expressam ou aprisionam, silenciam a sua própria capacidade de criar, de expressar sua autoria? E como tal "trama" tece um olhar docente que fragmenta, compartimentaliza e reduz a relação sinestésica que a criança possui com o mundo desde que se encontra no ventre materno, reduzindo as linguagens expressivas (as artes e o brincar) em meras técnicas sem sentido? Le Breton (2020) nos dá algumas pistas:

\footnotetext{
Na vida corrente não se adicionam percepções numa espécie de síntese permanente, mas vive-se uma experiência sensível do mundo. A todo instante a existência reclama a unidade dos sentidos. As percepções sensoriais impregnam o indivíduo em toda evidência.

Os sentidos trabalham conjuntamente a fim de tornar o mundo coerente e habitável. Não são eles que decifram o mundo, mas o indivíduo, através de sua sensibilidade e de sua educação (LE BRETON, 2020, p. 58-59).
}

Nesse contexto, aproximamo-nos de linguagens expressivas ávidas em encontrar um caminho de pesquisa e formação docente que toque, sensibilize e favoreça o olhar do(a) professor(a) sobre a sua própria história, o percurso formativo (pessoal e profissional) que o(a) constitui e que contribui para a construção de concepções e práticas sobre essas linguagens na educação infantil conectadas pela dimensão estética. Como possibilitar que esse sujeito construa uma narrativa de si? Uma narrativa que constitua para quem narra um processo de autoformação e não a descrição de fatos que se contam sem estar implicado com eles. Assim, compreendemos que a discussão sobre "pesquisaformação", que nesta perspectiva de pesquisa assume com essa junção de palavras a sua inextricável relação, é fundamental antes de narrar o processo de formação vivido em um coletivo de professores e professoras de crianças de 4 meses a 5 anos e II meses em uma instituição educativa municipal da Rede Municipal de Niterói /Unidade Municipal de Educação Infantil Professora Lisaura Machado Ruas.

Desse modo, a Pesquisa Narrativa (auto)biográfica contribui para pensar outras formas de expressão dos sujeitos que os considerem nas suas múltiplas dimensões (cognitiva, afetiva, psicomotora etc.), oportunizando processos formativos que ressaltam a condição autônoma e autoral de cada sujeito. Nesse sentido, Ferrarotti (2010), Bolívar (2014), Nóvoa (2010), Josso (2004), Bragança (2008) e Cunha (1997), entre outros, possibilitam a discussão. Ferrarotti (2010), como um dos pioneiros nesse campo de discussão, ao se debruçar sobre as especificidades do método biográfico, situa-o para além das fronteiras do modo clássico (positivista) de fazer ciência, pois, entre outros pressupostos teóricos e metodológicos, tal método "pretende atribuir à subjetividade um valor de conhecimento" (p. 36), o 
As linguagens expressivas e a Pesquisa Narrativa (auto)biográfica: contribuições para a formação docente...

que para esse autor é uma questão central que o motiva a perguntar: "como é que a subjetividade inerente à autobiografia pode tornar-se conhecimento científico"? (p. 43).

Com o intento de trazer para a presente investigação aspectos que respondam esta questão e legitimem o valor heurístico da Pesquisa Narrativa (auto)biográfica, Ferraroti (2010) menciona o que denomina "corte horizontal ou vertical" das narrativas no processo investigativo. Tais cortes são compreendidos como dimensões singulares e sociais que atravessam não só o ato de narrar, mas a própria condição existencial dos sujeitos.

Toda a vida humana se revela, até nos seus aspectos menos generalizáveis, como a síntese vertical de uma história social. Todo o comportamento ou ato individual nos parece, até nas formas mais únicas, a síntese horizontal de uma estrutura social [...], o nosso sistema social encontra-se integralmente em cada um dos nossos atos, em cada um dos nossos sonhos, delírios, obras, comportamentos. E a história desse sistema está contida por inteiro na história da nossa vida individual (FERRAROTTI, 2010, p. 44).

É preciso salientar, ainda, que esse autor ressalta que os seres humanos não são seres passivos na trama tecida entre as dimensões singular e social, mais sujeitos ativos que se apropriam do social que é mediatizado, filtrado, traduzido e passa a fazer parte do mundo psicológico e subjetivo de cada pessoa. Tal entendimento caminha no sentido de reivindicar um lugar para a subjetividade no contexto da produção do conhecimento científico (FERRAROTTI, 20I0).

Em consonância com esta abordagem, Antônio Bolívar (2014, p. II3) contribui para a discussão enfatizando que "la investigación narrativa y (auto)biográfica permite representar un conjunto de dimensiones de la experiencia que la investigación formal habitual deja fuera". Ele, também como Ferrarotti (2010), se preocupa com a questão epistemológica que problematiza o valor da subjetividade como conhecimento relevante para o desenvolvimento das pesquisas científicas. Para Bolívar (2014),

La subjetividad es, también, una condición necesaria del conocimiento social. El juego de subjetividades que se producen en un relato biográfico, basado en un diálogo consigo mismo y con el oyente en busca de una verdad consensuada, es un proceso dialógico, privilegiado de construcción de comprensión y significado. Es una manera de hacer aflorar y priorizar un yo narrativo y dialógico, con una naturaleza relacional y comunitaria (BOLÍVAR, 2014, p. II7).

É a partir desta perspectiva que Bolívar (2014) destaca o valor da Pesquisa Narrativa (auto)biográfica no sentido de construir novas metodologias de formação sensíveis à consideração dos professores e professoras como pessoas (portadoras de saberes/experiências constituídas no decorrer de uma trajetória que entrelaça vida e docência) que possam romper com concepções e práticas formativas apoiadas na escolarizaçãoleducação tradicional. 
A Pesquisa Narrativa (auto)biográfica, nessa perspectiva, se insere no movimento contemporâneo de reavaliar o que se compreende como formação. Não se trata, aqui, de um processo formativo cuja condução esteja nas mãos do outro ou de terceiros.

\begin{abstract}
A abordagem biográfica reforça o princípio segundo o qual é sempre a própria pessoa que se forma e forma-se à medida que elabora uma compreensão sobre o seu percurso de vida: a implicação do sujeito no seu próprio processo de formação torna-se assim inevitável. Desse modo, a abordagem biográfica deve ser entendida como uma tentativa de encontrar uma estratégia que permita ao indivíduo-sujeito tornar-se ator de seu processo de formação, por meio da apropriação retrospectiva do seu percurso de vida (NÓVOA, 2010, p. 13).
\end{abstract}

Em consonância com essas colocações, Nóvoa (2010) compreende a Pesquisa Narrativa (auto)biográfica como promotora de uma "nova epistemologia da formação" (p. 155) que também oportuniza processos inovadores de pensar e compreender a formação de professores. Para esse autor, os adultos se formam por meio de experiências, contextos e acontecimentos que perpassam sua trajetória de vida e formação; portanto, a ação educativa só adquire potencial formador quando consegue interagir com a lógica constituída por meio da trajetória pessoal e singular de cada um. Nesse sentido, a formação contínua é um processo pelo qual as trajetórias de vida podem se modificar, implicando uma construção paulatina desse adulto que se forma.

O entendimento de que o sujeito da pesquisa, ao narrar, provoca mudanças em si mesmo é compartilhado também por Delory-Momberger (2012), pois para a autora a narrativa, para além de ser um produto do "ato de contar", tem um poder e um efeito sobre o que se narra, e é esse poder de agir da narrativa que dá às histórias de vida esse potencial de mudança e desenvolvimento nos processos de formação, processos de mudanças que acontecem pela escolha e pela implicação dos sujeitos que estão imersos nos processos de formação, independentemente da posição que ocupem nesse processo, seja de pesquisador, seja de pesquisado, seja de formador ou de formado; na verdade, essa perspectiva dilui tais fronteiras e demarcações. Dessa forma, compreendemos que tanto o aporte teórico e metodológico desta pesquisa quanto a dimensão estética presente também nas linguagens expressivas contribuem para repensar/romper com as bases de uma concepção racionalizadora e hierárquica dos processos de formação, uma educação que se apoia na "verborragia" do professor(a), que silencia o educando e ele mesmo, o profissional da educação, como sujeitos que problematizam o conhecimento em uma relação visceral com a vida. O professor(a) fala, do seu pedestal de "dono do conhecimento", enquanto o educando "tábula rasa" deve se submeter e apenas ouvir. Mente e corpo são dicotomizados e separados quando se pensa o processo de aprendizagem que é entendido como acúmulo de conteúdos fragmentados, desarticulados e descontextualizados (FREIRE, 1998). 
Na contramão da concepção tradicional de educação, a Pesquisa Narrativa desenvolve uma investigação que é formativa para todos os que estão inseridos no processo investigativo, como bem coloca Inês Bragança (2008, p. 74):

Buscamos um diálogo partilhado em que pesquisadores e sujeitos responsabilizamse pelo processo de construção de saberes. [...] A principal contribuição destacada é a possibilidade de escuta e de intercâmbio com sujeitos que, na ciência clássica, foram tomados como objetos. Buscamos a valorização da vida, das vozes, das subjetividades, como alternativa de investigação para reconstruir a história e as políticas educativas e também as práticas de formação.

A partir desse momento é preciso perguntar: como as linguagens expressivas que são perpassadas pela dimensão estética contribuem também para ouvir as vozes docentes? Contar uma história que não pode ser contada pelo outro é uma narrativa de si atravessada pelas produções de sentidos que o vivido proporcionou a cada sujeito narrador e que precisa ser ouvida pelo outro e pelo próprio sujeito que narra.

\title{
As linguagens expressivas e a dimensão estética do ser humano dialogando com a Pesquisa Narrativa: revendo o exercício da docência
}

\begin{abstract}
"Cada nova realidade estética redefine a realidade ética do homem. Porque a estética é a mãe da ética. As categorias de "bom" e "mau" são, em primeiro lugar e antes de tudo, categorias estéticas”.5.
\end{abstract}

A estética é uma palavra introduzida por Baumgarten nos meados do século XVIII; designava a “ciência (filosófica) da arte e do belo". Entretanto, o estudo da arte remonta à Antiguidade e foi muito discutida, a princípio, por filósofos como Platão e Aristóteles, entre outros, designada como poética "arte produtiva, produtiva de imagens" (ABBAGNANO, 20I4, p. 4I6).

De acordo com Morin (2017), a palavra aisthesis é derivada do grego cujo significados se relacionavam com os sentimentos e as sensações, mas, antes de ser uma característica específica das artes, se relacionava com o que há de sensível no ser humano, o que favorece a desconstrução da concepção binária de estética em que só existe o belo ou o feio, como se a estética se reduzisse a essa visão. A estética mobiliza sensações, percepções e sentimentos que podem encantar ou inquietar, angustiar e problematizar.

É no interior dessa discussão que a pesquisadora italiana Vea Vecchi (2017), uma das primeiras atelieristas da história da abordagem malaguzziana ${ }^{6}$, afirma a dimensão estética como elemento vital no

\footnotetext{
${ }^{5}$ Discurso pronunciado pelo Prêmio Nobel Josif Brodskij (HOYUELOS, 2020, p. 27).

${ }^{6}$ Loris Malaguzzi foi um dos fundadores do Sistema Educacional Municipal da cidade de Reggio Emília, no norte da Itália, após a destruição da cidade durante a Segunda Guerra Mundial. Ele, educador, construiu junto com a comunidade local (pais, crianças, professores(as), entre outros) uma abordagem denominada Pedagogia
} 
processo de formação e desenvolvimento humano. Sobre essa temática, destaca que a formação docente não pode esquecer nem da beleza nem da estética, pois corre o risco de, ao ignorar a dimensão estética, construir um olhar que não enxergue tal dimensão nas crianças, jovens e professores que estão à nossa frente, o que não favorece a saúde psíquica deles nem possibilita ter esperança no futuro. Ela propõe a beleza e a estética não no sentido superficial como a atualidade tem proposto, mas como parte de direitos fundamentais e inalienáveis que podem promover saúde e bemestar à humanidade (VECCHI, 2017).

Neste ponto, cabe a pergunta: o que seria a dimensão estética para Vea Vecchi? Ela responde, mas afirma que é difícil dizer claramente o que se entende por dimensão estética.

Creo que se trata de una actitud cotidiana, una relación empática y sensible con el entorno, un hilo que conecta y ata las cosas entre sí, un aire que lleva a preferir un gesto a otro, a seleccionar un objeto, a elegir un color, un pensamiento; elecciones en las que se percebe armonía, cuidado, pacer para la mente y para los sentidos. La dimensión estética presupone una mirada que descubre, que admira y se emociona. Es lo contrario de la indiferencia, de la negligencia y del conformismo (VECCHI, 2006, p. I5-16).

A autora italiana ainda acrescenta que a dimensão estética faz parte de uma estrutura de pensamento que evolui e que em situação de aprendizagem pode sustentar e alimentar um conhecimento que não apenas se nutre de informação, mas conduz a uma relação de sensibilidade, de escuta e empatia com as coisas, com o entorno, possibilitando conexões. Tais pensamentos e conhecimentos se configuram como algo transversal que articula diferentes áreas do conhecimento, cada qual com a sua linguagem 7 . Assim, a dimensão estética não se articula somente à arte; é uma modalidade de busca e lugar de experiência.

Ostetto (2006; 2016) e Kolb-Bernardes (2010; 2018) desenvolvem pesquisas considerando a arte, a dimensão estética e os processos formativos como um convite à "transvisão" ao construir um olhar para além das certezas e do que está posto como verdade absoluta. Ostetto (2006) afirma que as propostas de formação docente são, comumente, herméticas, se fecham e se isolam no espaçoltempo da escola. Pensar outras possibilidades de ambientes formativos é geralmente descartado. Tal forma de pensar a formação docente limitada pelos muros da escola é uma forma

Relacional, cujos pilares são o diálogo, a escuta e o protagonismo da criança no processo de aprendizagem. Tal Pedagogia propõe a metáfora da escola como um grande ateliê onde as diferentes linguagens são utilizadas para a experimentação e a construção do conhecimento (RINALDI, 20I2).

7 Para a abordagem malaguzziana, como no poema as "Ao contrário, as cem existem", as linguagens são múltiplas, pois através delas os sujeitos produzem cultura e se apropriam da cultura, do mundo simbólico e dos processos de produção de sentidos. Assim, existem as linguagens poéticaslexpressivas e outras linguagens, como a matemática, a física, as ciências e as especificidades das materialidades de que cada ciência se ocupa (VECCHI, 2017). 
As linguagens expressivas e a Pesquisa Narrativa (auto)biográfica: contribuições para a formação docente...

tradicional de pensar o processo pedagógico apoiada nas ideias de controle, certezas absolutas, únicas, em detrimento da diversidade de vozeslhistórias que ecoam nesse espaço. É diante desse cenário que a arte problematiza as certezas, as verdades únicas, e propõe olhar os sujeitos e o mundo com estranhamento, isto é, olhar o familiar como estranho, estimulando a busca, a investigação perpassada pela estética e pela relação de sinestesia que cada ser possui com seu entorno. As linguagens expressivas nos desafiam a olhar a inteireza de cada pessoa e descobrir um vasto mundo, das coisas consideradas diminutas, ínfimas até a grandiosidade que é o mundo, os seres e os fenômenos.

Assim, é fundamental pensar um processo formativo que promova a conexão dos professores(as) com suas percepções, seus sentimentos e suas histórias (profissionais e de vida) que os(as) constituem como seres em relação com o mundo, com o seu entorno e com os outros sujeitos. Nesse sentido, Terragrosa (2017), ao tratar da expressão artística no contexto de discussão da Pesquisa Narrativa de aporte (auto)biográfico, convoca os pesquisadores desse campo para olhar o sujeito da pesquisa com base nas múltiplas dimensões que o constituem. Aquele que narra a sua história, quando fala, não conta apenas com as palavras; conta com expressões faciais, gestos que acompanham cada palavra dita, o movimento do corpo que expressa ideias, sensações e emoções que o percorrem, revelando um ser complexo e multifacetado. Diante do sujeito-investigador da pesquisa, uma narrativa acontece, sendo dita por meio de diferentes linguagens.

Podemos destacar que a narração aparece em uma oralidade que não se compõe apenas de palavras, mas de gestos, olhares, corporalidade, desenhos ou poemas, já que a escrita, a narração, se realiza através diversas manifestações, como o têxtil, as imagens, as gravuras, a dança, o teatro etc. Tudo isso constitui os relatos que são tecidos entre diversas dimensões para desvendar a complexidade das vivências. Portanto não podemos ficar na dimensão da escrita textual, da oralidade, inclusive; integramos a completude das pessoas a partir do intercâmbio no qual os corpos expressam também o modo de vivenciar certas situações. Assim, combinar a narração e a dimensão artística favorece outros modos de expressar os relatos (TERRAGROSA, 2017, p. 310).

Delory-Momberger (2012) se junta a esta discussão enfatizando a função das diferentes linguagens presentes na cultura que contribuem para que cada pessoa seja capaz de produzir sentidos sobre a sua própria trajetória, pois, como enfatiza a autora, é importante que a pesquisa biográfica se constitua em um espaço onde os sujeitos possam dar forma e significar suas experiências e os acontecimentos de sua existência por meio das linguagens culturais e sociais, entendendo-se linguagem aqui em seu sentido amplo, que pode incluir códigos, esquemas, figuras de discurso etc.

Nesse ponto, sabe-se que muitas formas de ver e fazer a educação em nossa sociedade ainda se apoiam em uma visão fragmentada do ser humano, dando ênfase aos processos de cognição (raciocínio, memorização etc.), em detrimento de outras formas de sentir/perceber que também são necessárias ao ato de conhecer e aprender. É como se a cabeça e o corpo estivessem separados. Como 
é dito no trecho da poesia “Ao contrário, as cem existe”, escrita pelo educador italiano Loris Malaguzzi (1999), "a criança tem cem linguagens (e depois cem, cem, cem), mas roubaram-lhe noventa e nove. A escola e a cultura lhe separam a cabeça do corpo. Dizem-lhe: de pensar sem as mãos, de fazer sem a cabeça, de escutar e de não falar.” (MALAGUZZI,1999, p. 5).

\section{É possível romper com tais concepções e práticas?}

Nóvoa (1995), Josso (2004), Cunha (1997), Luciana Ostetto (2016), Kolb-Bernardes (2018), entre outros autores que valorizam a narrativa e as histórias de vida numa perspectiva de pesquisaformação, propõem caminhos investigativos que potencializem o ato de rememorar, fazendo fluir a expressão de todos os sujeitos envolvidos. Narrar não é contar tal como aconteceram os fatos em sua expressão mais literal possível. A narrativa "é a representação que deles faz o sujeito e, dessa forma, pode ser transformadora da própria realidade" (CUNHA, 1997, p. 2).

Esses pesquisadores entendem que as linguagens expressivas podem favorecer a construção de um espaço/tempo que cria várias formas de as vozes dos sujeitos serem ouvidas, que possibilita conexões e trajetórias que conduzem, visceralmente, professores e professoras a irem ao encontro das suas raízes crianceiras, como diria Manoel de Barros (2019). Raízes do ato criador e poético que nos fazem rememorar e refletir sobre nossas concepções e práticas estéticas (e éticas) que podem invisibilizar ou dar visibilidade ao ser inteiro que são as crianças e seus professores(as) (OSTETTO, 2010).

Essas linguagens abrem caminhos para que, além da palavra (escrita ou oral), outras formas de sentir e perceber auxiliem no exercício de se colocar no lugar do outro; um exercício de alteridade que aproxima, constrói vínculos e entrelaça os sujeitos envolvidos no processo investigativo. Em nosso modo de compreender, o diálogo entre as linguagens expressivas e a Pesquisa Narrativa abre um tempolespaço para que vida e formação (produções de sentidos sobre o exercício da docência ao longo da existência) sejam indissociáveis.

\section{As linguagens expressivas e a estética em um coletivo de professores: vozes, movimentos e sensações que reverberam em cada sujeito}

Este texto, como assinalado acima, é fruto de uma pesquisa realizada desde 2017 para uma tese de doutorado ainda em fase de elaboração. $O$ campo de pesquisa foi escolhido devido à trajetória de vida, trabalho e formação que uma das autoras possui com a Unidade Municipal de Educação Infantil Professora Lisaura Machado Ruas desde 20II, ao iniciar o trabalho na instituição com o cuidado e a educação de crianças de 4 meses a 5 anos de idade em agosto daquele ano. Uma história de coordenação pedagógica, ocupando o cargo de pedagoga concursada, que foi sendo construída na 
As linguagens expressivas e a Pesquisa Narrativa (auto)biográfica: contribuições para a formação docente...

relação com os diferentes sujeitos que constituem a comunidade educativa. Desde 2019, possuímos na UMEI uma equipe toda concursada, pois a instituição passou oito anos recebendo professores contratados pelo período de dois ou três anos, o que tinha como consequência a não continuidade ${ }^{8}$ de todo o investimento de formação que havíamos feito até o contrato acabar.

A formação continuada e em serviço, que se constitui como base desta pesquisa, ocorreu com dezesseis professores(as), a direção (diretora geral e adjunta) e a pesquisadora, que, nesse contexto, como foi dito, ocupa a função de pedagoga da instituição. A escolha do grupo de professoras seguiu os seguintes critérios: I) Ter formação de nível médio ou graduação em Pedagogia; 2) Ter mais de um ano de atuação profissional em uma unidade municipal de educação infantil; 3) Explicitar/se identificar com as atribuições de cuidado e educação como professor(a) da educação infantil; 4) Ter interesse em aprofundar seus conhecimentos nessa área. $O$ objetivo central desta pesquisa é refletir sobre a importância das diferentes linguagens expressivas (como as artes e o brincar) no processo de formação continuada e em serviço de professores de educação infantil e suas repercussões no trabalho docente. Para este relato, selecionamos algumas etapas do processo de pesquisa e formação vivido por três das professoras. Nossas formações, antes da pandemia do COVID-19, ocorriam toda quarta-feira à tarde, das 15 horas às 17 horas. Após as primeiras ações de restrição e distanciamento social da prefeitura, no dia 16 de março, nossas formações reiniciaram no final de maio de 2020 , mediante encontros remotos pela plataforma Zoom, mantendo a quarta-feira à tarde, mas das $13 \mathrm{~h} 30 \mathrm{~min}$ até as 16 horas.

Metodologicamente, nosso movimento foi de propor "experiências estéticas" que contribuíssem para o autoconhecimento de si e do outro tecido e compartilhado em "Rodas de conversa".

De acordo com Barbieri e Baroukh (2017, p. 37), “Todos nós temos experiências estéticas desde que nascemos, porque elas se relacionam com a estrutura que vai se criando tanto em nosso pensamento como em nossa percepção”. Elas são constituídas por texturas, aromas, o que ouvimos e vemos ao longo da vida.

Nossas "Rodas de conversa" ocorreram tanto presencialmente quanto remotamente, pois as narrativas das pessoas que participaram desta pesquisa circularam entre nós, permitindo identificações, exercícios de alteridade e produções de sentidos coletivos diante da história ouvida ou narrada. No momento da pandemia, nossas imersões nos relatos do outro social nos dava a sensação e a percepção de estarmos juntos, conectados. Desse modo, optamos pela conversa como metodologia de pesquisa

\footnotetext{
${ }^{8}$ A escola não conseguia colher os frutos das formações a longo prazo, mas entendemos que contribuímos para a formação dos profissionais que passaram por nossa unidade.
}

Olhar de professor, Ponta Grossa, v. 24, p. I-18, e-17624.080, 2021.

Disponível em <https://revistas2.uepg.br/index.php/olhardeprofessor> 
que rompe com o modelo clássico e positivista de realizar uma entrevista, em que o pesquisador pensa o sujeito como objeto e, por isso, busca controlar o que é dito, fechando o sujeito investigado em um cerco de perguntas tendenciosas que não são encaradas pelo entrevistado como questões pertinentes e significativas (SANCHES; RIBEIRO; SOUZA, 2018). Procuramos

\begin{abstract}
Uma pesquisa que aposta no acontecimento da conversa como metodologia de investigação, como um golpe que desafia a polícia metodológica hegemônica, tão bem representada por questionários, roteiros, procedimentos rígidos. Ao apostar na conversa buscamos, na relação de pesquisa, abrir-nos ao acontecimento e aos possíveis que ele conjura, mesmo que isso, por vezes, possa significar a necessidade de desconstruçãolreconstrução da própria investigação (SANCHES; RIBEIRO; SOUZA, 2018, p. 33).
\end{abstract}

Para esses autores, a conversa se aproxima da "micropolítica" elaborada no cotidiano, oportunizando que vozes e gestos diversos, divergentes, convergentes, entre outros, sejam legitimados como narrativas vitais para a compreensão dos sujeitos, seus contextos e seus modos e, assim, "abrir horizontes de possibilidade para que possamos vivenciar o assombro, a dúvida, o estranhamento, a indagação e o encantamento na pesquisa" (SANCHES; RIBEIRO; SOUZA, 20I8, p. 37), o que se coaduna com as escolhas que temos feito durante o processo de investigação.

Em 2019, após a apresentação do projeto de pesquisa ${ }^{9}$, dos objetivos geral e específicos ao grupo de professores e professoras da unidade, demos início ao processo de pesquisa e formação. Aqui relatamos os procedimentos organizados para possibilitar as narrativas docentes, sobretudo neste momento inicial da escuta e do diálogo, que continuam sendo feitas. Inicialmente, para desencadear as primeiras narrativas, apresentei um poema de Manoel de Barros (2019, p.15), intitulado "Manoel por Manoel", que trata da infância em suas relações com o ato de fazer de conta e a criação.

\title{
Manoel por Manoel
}

Eu tenho um ermo enorme dentro do olho. Por motivo do ermo não fui um menino peralta. Agora tenho saudade do que não fui. Acho que o que faço agora é o que não pude fazer na infância. Faço outro tipo de peraltagem. Quando era criança eu deveria pular muro do vizinho para catar goiaba. Mas não havia vizinho. Em vez de peraltagem eu fazia solidão. Brincava de fingir que era pedra, era lagarto. Que era navio. Que sabugo era um serzinho mal resolvido e igual a um filhote de gafanhoto. Cresci brincando no chão, entre formigas. De uma infância livre e sem comparamentos. Eu tinha mais comunhão com as coisas do que comparação. Porque se a gente fala a partir de ser criança, a gente faz comunhão: de um orvalho e sua aranha, de uma tarde e suas garças, de um pássaro e sua árvore. Então eu trago das minhas raízes crianceiras a visão comungante e oblíqua das coisas. [...] Era o menino e o sol. $O$ menino e o rio. Era o menino e as árvores (BARROS, 2019, p. 15).

\footnotetext{
${ }^{9}$ Foi apresentado ao grupo de professores(as) um termo de consentimento livre e esclarecido como documento que legitima a participação oficial deles na pesquisa, além de informar que as entrevistas narrativas poderiam ser gravadas.
}

Olhar de professor, Ponta Grossa, v. 24, p. I-18, e-17624.080, 2021.

Disponível em <https://revistas2.uepg.br/index.php/olhardeprofessor> 
Conversamos um pouco sobre o poema e depois, como em um exercício de alteridade - de experimentar o que estava propondo para o grupo de professores e professoras -, mostrei um desenho de um bicho feito por mim, com pequenos frutos da mangueira com patas de palitos de fósforo usados a partir das minhas lembranças do ato criador e imaginativo na minha infância. A seguir, li um trecho do memorial elaborado para a tese de doutorado e que se reportava à seguinte rememoração:

\footnotetext{
"Ao buscar minhas memórias, meu intento é encontrar o início de uma trama, produções de sentido que faço sobre a arte - como atividade de criação e imaginação -, a criança, a infância, a educação infantil e à docência. Desse modo, procuro lembranças e registros do ato criador pulsando e se manifestando em meu percurso pessoal e profissional.

E, assim, começo a me lembrar das coisas de criança, "da minha infância querida que os anos não trazem mais!", como bem disse Casimiro de Abreu, na poesia "Meus oito anos".

Lembro-me do quintal, em Santa Eugênia, Nova Iguaçu, Baixada Fluminense, Rio de Janeiro. Morei por 33 anos nesse local e tenho muitas lembranças, como as brincadeiras de crianças, de ter mais irmãos (quatro irmãos e uma prima que morava conosco) do que brinquedos. De brincar com as folhas das árvores, brincar com água, tomar banho de chuva, de fazer de conta que a ventania me faria voar, de me imaginar voando, de brincar de balanço de corda e pneu preso a uma grande mangueira. De pular do muro para dar mais impulso ao balanço e tentar tocar o telhado de casa com as pontas dos pés. De imaginar que as pequenas mangas verdes no chão poderiam ser outra coisa como bois e cavalinhos, logo depois de fincar em cada "manguita" fósforos usados para fazer as patas.

Das brincadeiras de casinha, lembro de pegar latas vazias encher com água, acender o fogo entre tijolos e cozinhar pequenos punhados de macarrão.

Muito antes de me tornar professora primária, eu brincava com as minhas poucas bonecas de escola. Eu utilizava as últimas folhas de um caderno escolar já sem uso e reutilizava o plástico que encapava tais cadernos. Gostava de confeccionar o material escolar das bonecas: costurava pequenas bolsas (aos oito anos de idade) com os retalhos de panos que minha mãe dona de casa e costureira me dava. Recortava pedaços de papel para fazer minicadernos e fazia ponta no lápis de escrever até ficar bem pequeno. Colocava as bonecas enfileiradas, uma atrás da outra e escrevia no muro do quintal (com carvão ou pedaço de tijolo) como se fosse um quadro. No meu mundo de faz de conta as alunas deveriam ficar quietas e copiar do quadro. Uma cópia com letra bonita, em um caderno bem cuidado e limpo. Sem borrões" (NASCIMENTO, 2019, p. 8-9).
}

Posteriormente, apresentei ao grupo de professores um tópico através do seguinte questionamento: quais lembranças que você possui do ato de criar e imaginar na infância?

Com base nessa pergunta, pedi aos docentes que iniciassem a rememoração por meio de uma linguagem artística: do desenho (uma das linguagens desencadeadoras de narrativas durante a pesquisaformação que com o decorrer da investigação foram se ampliando). Escolhi o desenho, a princípio, por todo o significado que essa linguagem tem na minha história de vida, uma linguagem familiar e intensa que me acompanhou como meio de expressar emoções, ideias, pensamentos, desejos etc. 
Os professores e as professoras produziram seus desenhos (com os materiais disponíveis: pincéis, lápis de cor, lápis de cera e guache. Também disponibilizei outros menos usuais 10 na escola: folha de papel canson $\mathrm{A} 3$, bola de gás cheia, carvão, palitos de picolé, canudinhos, garfos de plástico etc.), todos em volta de uma grande mesa arrumada para a atividade na sala de multimeios - sala que possui alguns recursos audiovisuais como televisão e computador, além do acervo de livros infantis e jogos. É o lugar onde são realizadas, comumente, as formações docentes"'. Para o mergulho nas lembranças, também coloquei uma música instrumental que reproduzia sons da natureza. Após a elaboração pictórica de uma lembrança, pedi a cada professor e professora que falasse de suas produções em suas relações com a infância e o ato de criar e imaginar. Nesse dia, gravei as narrativas de todos os professores(as), que foram transcritas posteriormente. Nesse sentido, alguns trechos são mencionados abaixo, mas garantindo o anonimato das pessoas envolvidas.

\section{Narrativas das professoras: resgatando nossas raízes crianceiras pelas linguagens expressivas (o brincar e a arte)}

Esta primeira experiência de pesquisa-formação nos mostrou que na investigação, embora tenha seus princípios (objetivos) norteadores teóricos e metodológicos, como mostramos antes, não podemos - nem é a proposta da Pesquisa Narrativa (auto)biográfica - controlar as narrativas de tal forma que os sujeitos da pesquisa digam o que queremos ouvir como resposta que mais se encaixa à temática focada. Afinal, queríamos (e seguimos) uma caminhada que garantisse a todos os envolvidos um espaçoltempo de autoria na construçãolinterpretação da sua própria história. Em função das próprias narrativas docentes, ampliamos o nosso objetivo geral, que, no projeto de pesquisa inicial, focava apenas as concepções de arte dos professores da educação infantil e quais as consequências dessas formas de pensar o artístico nos fazeres desses docentes junto às crianças. Nesse sentido, conforme já foi apresentado, ampliamos nosso objetivo geral para: refletir e discutir sobre a importância das diferentes linguagens expressivas (como as artes e o brincar), considerando a dimensão estética, de professores de educação infantil durante a formação continuada e em serviço e suas repercussões no trabalho docente.

\footnotetext{
10 Queria observar suas escolhas, a capacidade de resgatar suas raízes crianceiras e ousar utilizar outros materiais que despertassem maior expressão da criatividade ou se os rejeitariam.

II Com certa frequência, antes da pandemia do COVID-19, sempre realizamos formações em outros espaços, como na Feira de Tradições Nordestinas, em São Cristóvão, no Rio de Janeiro, na Escola do Circo, também na cidade do Rio de Janeiro, e em diferentes museus.
} 
Desse modo, trazemos agora as narrativas das três professoras selecionadas para este relato, narrativas estas atravessadas pelos sentidos atribuídos por elas às suas experiências com as linguagens expressivas, em que o brincar possibilita exercícios de criação e imaginação.

Professora A - Desenhou a si e a uma amiga deitadas embaixo de uma tamarineira comendo tamarindo. Nome da obra: A Infância.

"Uma lembrança bem da infância (...) é uma lembrança na casa de uma colega minha Valéria, a gente brincava muito lá... Na casa dela tinha muita pedreira, e lá no meio da pedreira tinha essa tamarineira, então de tarde a gente ia para lá, deitava lá embaixo e ia comendo tamarindo ali o dia todo, então era assim muito legal, e eu ia muito para essa casa, a gente brincava de tudo, de correr em cima das pedras, sabe, de cima da pedreira, igual moleque mesmo, era muito legal, essa era o retrato aqui meu e Valéria."

Professora B - Desenhou a si e à irmã numa paisagem com árvores e na lama. Por isso, ambas possuem nas mãos bolas de lama. Não quis dar nome à sua obra.

“É uma das lembranças da minha infância, eu e minha irmã, lá em casa, é na mangueira, de vez em quando a gente subia, mas a nossa brincadeira principal era fazer bolinhos de lama, na terra mesmo, aí é por isso que está bem molhado, tem os bolinhos, e aí esses bolinhos que a gente colocava a massa no pote de manteiga, aí fazia bolinho de um andar, de três, castelinho... e aí ia... a imaginação ia... a gente tinha uns cinco, seis anos, sete, por aí".

Professora C - Desenhou uma cabaninha feita com uma cama beliche e panos (lençóis) por cima. Nome da obra: A Cabana do Papai.

"O que eu lembrei, sempre ficou muito marcado na minha memória, meu pai, ele era enfermeiro, ele é aposentado, mas ele era enfermeiro e trabalhava muito, e assim ele era daquele tipo de pai que menina não podia brincar muito no quintal porque não podia cair, não podia marcar as pernas, não podia marcar os braços, não podia ter marca, então eu lembro que quando a minha mãe falava 'amanhã seu pai está em casa, não vai estar de plantão, seu pai vai estar em casa', a gente já dormia naquela expectativa, porque o dia que ele estava em casa ele acordava cedo, fazia o café, e no nosso quarto tinha uma beliche, onde a gente dormia, nós somos quatro irmãs, e ele fazia uma cabana na beliche e trazia o café para a gente tomar embaixo dessa cabaninha, aí entrávamos ali embaixo eu, minhas quatro irmãs e meu pai, era uma loucura, ficava bem apertado, mas, assim, a gente esperava por aquele momento meses, às vezes, porque a gente só via meu pai entrar por uma porta e sair pela outra, só vinha, tomava banho trocava de roupa e saía, então esse dia era bem esperado, ele vinha com aquele sorrisão, com café, a gente entrava ali e ele contava história, ele falava um monte de coisas: 'está estudando? Está correndo no quintal? E essa marca aí no joelho?'."

\section{As primeiras reflexões, impressões das narrativas}

Ao ler as narrativas, consideradas por Ferrarotti (2010) como fontes primárias de uma investigação ${ }^{12}$, podemos perceber como elas são encharcadas de percepções e sensações legitimadas pelos nossos sentidos na relação com o outro social, um parceiro (ou parceiros de brincadeiras, criação

\footnotetext{
12 Fontes secundárias: documentos escritos, documentos elaborados por instituições oficiais. Em nosso caso, 0 Ministério da Educação (FERRAROTTI, 2010).
} 
e faz de conta) que nunca perderá seu lugar em nossas produções de sentidos enquanto tomamos consciência do impacto do que escolhemos contar, priorizar, como elemento fundante da nossa formação pessoal e profissional. O que foi compartilhado conosco e que também compartilhamos em uma roda, como em uma comunidade narrativa, como diria Walter Benjamin (1994), fez-nos iniciar a criação de laços identitários, vínculos e ao mesmo tempo a postura ética e de alteridade de se colocar no lugar do outro. Entender a história do outro que ao mesmo tempo nos assemelha, nos singulariza e ajuda a olhar nossa própria caminhada no grupo que também nos permite vislumbrar nossas perspectivas; um parceiro de descobertas e explorações, como bem narra Eduardo Galeano (2019) na poesia "A função da arte".

Diego não conhecia o mar. $\bigcirc$ pai, Santiago Kovadloff, levou-o para que descobrisse o mar. Viajaram para o Sul. Ele, o mar, estava do outro lado das dunas altas, esperando. Quando o menino e o pai enfim alcançaram aquelas alturas de areia, depois de muito caminhar, o mar estava na frente de seus olhos. $E$ foi tanta imensidão do mar, e tanto seu fulgor, que o menino ficou mudo de beleza. E quando finalmente conseguiu falar, tremendo, gaguejando, pediu ao pai: Me ajuda a olhar! (GALEANO, 2019).

E, à medida que trilhamos essa caminhada de pesquisa-formação, vamos nos dando conta, como Diego em frente ao mar, da imensidão de vozes que ressoam junto com a nossa voz e as dos professores(as) envolvidos nesta pesquisa. Vozes de familiares, amigos e outros sujeitos que ecoam dentro de nós e dos professores pelas lembranças, pelas memórias de um tempo que vive, lateja e se faz presente por meio do que dizemos e fazemos como profissionais da Educação, como bem coloca Ferrarotti (2010) ao fazer menção aos grupos restritos (família, escola e outros) e o papel que esses grupos têm na construção de concepções e práticas ao longo do percurso formativo de cada sujeito.

Essas vozes ecoaram em nossas narrativas e nas dos professores(as) envolvidos(as) nesta investigação. Mães, pais, irmãos, primas, companheiros de jogos infantis, entre outros, estiveram presentes no ato de rememoração como elementos fundamentais das interações travadas em um dado contexto social.

Para além das relações entre os sujeitos que são travadas no contexto da brincadeira, o ato de criar através do brincar é narrado também por meio de outra relação, a relação intensa e afetiva com o ambiente que envolve cada sujeito na sua inteireza, como diria Ostetto (2017). Como em um movimento uníssono, mente e corpo, razão e emoção são colocados a serviço do ato criador ao mesmo tempo que permitem conhecer a si mesmos (através das habilidades já consolidadas), ao outro que brinca junto (acompanha, partilha e dialoga) e ao que está ao redor (conhecer os elementos que constituem a natureza na sua materialidade). Tamarineiras, mangueiras, pedras, terra molhada, barro molhado e plantas que viraram bonecas são elementos da natureza que são ressaltados nas histórias contadas pelos narradores desta pesquisa. 
As linguagens expressivas e a Pesquisa Narrativa (auto)biográfica: contribuições para a formação docente...

Atualmente, desde maio de 2020, estamos ampliando nossos estudos sobre as diferentes linguagens: as linguagens da natureza (tintas naturais, argila, terra etc.), o desenho e a pintura, o que nos levou a estudar a teoria das cores em suas relações com a luz ou a ausência dela; fotografia, cores e luzes naturais e artificiais, luz e sombra e teatro de sombras, entre outras. Durante a pandemia, seguimos realizando às quartas-feiras estudos teóricos (com textos, lives, filmes etc.) e experimentações estéticas feitas por cada professor ou professora em sua residência. Experimentações com registros escritos, fotográficos e filmados da relação dos sujeitos com a materialidade dos objetos utilizados em cada linguagem, o que posteriormente favorecia nos próximos encontros a divulgação por cada professor(a) do que foi feito, visto, sentido ou rememorado a partir das experiências. A cada formação, conversávamos como foi viver a "experiência estética", investigar as materialidades, como as tintas naturais, a argila, a terra, água, entre outros materiais próprios das artes visuais, como já mencionamos. Nós pedíamos que, em uma ficha com perguntas, a cada experiência, os professores e as professoras contassem como foi ter contato com aquelas materialidades, se lembravam (por meio dos cheiros, texturas, sensações táteis etc.) não apenas de fatos da infância, mas de outros momentos ao longo da vida. Iniciávamos as perguntas sempre pela sinestesia, pela memória sinestésica que possuímos. Exemplo: ao manipular a materialidade da argila, quais cheiros você sentiu? $\mathrm{O}$ que $\circ$ tato Ihe provocou?

Posteriormente, após a familiarização com a materialidade dos materiais, seguíamos refletindo sobre quais possibilidades pedagógicas de experimentação, explorações que poderíamos propor às crianças no planejamento. Afinal, como elaborar um planejamento, atravessado pela concepção da escola como lugar de pesquisa e experimentação, sem conhecer e viver experiências sensíveis e estéticas com a temática focada? Tal processo alimentou as propostas e os planejamentos feitos pelos(as) professores(as) divulgados no Facebook para as famílias e as crianças de nossa escola. Assim, os professores e as professoras estavam propondo para as crianças, no Facebook, durante a pandemia e com a mediação de seus familiares, ações encharcadas por suas experiências, discussões teóricas ${ }^{13} \mathrm{e}$ produção de sentidos realizados durante o processo formativo. Sentimos que foi preciso resgatar a sinestesia corporal como elemento fundamental para o aprendizado, ou seja, pensar um processo que enxerga a inteireza de adultos e crianças como sujeitos que se expressam, se comunicam e ampliam sua relação consigo mesmos e com o mundo via utilização das diferentes linguagens.

\footnotetext{
${ }^{13}$ Não só discussões das ações pedagógicas, mas estudos sobre cada materialidade utilizada nas artes visuais e nas brincadeiras das crianças.
}

Olhar de professor, Ponta Grossa, v. 24, p. I-18, e-17624.080, 2021.

Disponível em <https://revistas2.uepg.br/index.php/olhardeprofessor> 


\section{Referências}

BARBIERI, S.; BAROUKH, J. A. (coord.); ALVES, M. C. C. L. Interações: onde está a arte na infância? 3. ed. São Paulo: Edgard Blucher, 2017.

BARROS, M. Meu quintal é maior do que o mundo. Antologia. 9. ed. Rio de Janeiro: Companhia das Letras, 2019.

BENJAMIN, W. Obras escolhidas. Magia e técnica, arte e política: ensaios sobre literatura e história da cultura. 7. ed. Trad. Sérgio P. R. São Paulo: Brasiliense, 1994.

BERNARDES, R. K.et al. Segredos do coração: a escola como espaço para o olhar sensível. Caderno Cedes, Campinas, v. 30, n. 80, p. 72-83, jan./abr. 2010.

BERNARDES, R. K. De rios e córregos que desaguam em narrativas autobiográficas: o ateliê de arte como espaço-tempo de caminhar para si. In: VIII CONGRESSO INTERNACIONAL DE PESQUISA (AUTO)BIOGRÁfICA, 8, 20I8, São Paulo. Anais [...]. São Paulo: Unicid, 2018.

BOLÍVAR, A. A expressividade epistêmico-metodológica da pesquisa (auto)biográfica. In: ABRAHÃO, M. H. M. B.; BRAGANÇA, I. F. S.; ARAÚJO, M. S. (Orgs.) Pesquisa (auto)biográfica, fontes e questões. Curitiba: CRV, 20I4. p. II3-I28.

BRAGANÇA, I. F. S. Histórias de vida e formação de professores/as: um olhar dirigido à literatura educacional. In: SOUZA, E. C.; MIGNOT, A. C. V. et al. Histórias de vida e formação de professores. Rio de Janeiro: Quartet/Faperj, 2008. p. 65-8I.

CUNHA, M. I. Conte-me agora! As narrativas como alternativas na pesquisa e no ensino. Revista da Faculdade de Educação, São Paulo, v. 23, n. I-2, p. I-7, jan./dez. 1997.

DELORY-MOMBERGER, C. A pesquisa biográfica: projeto epistemológico e perspectivas metodológicas. In: Abrahão, Maria Helena Menna Barreto; PASSEGI, Maria da Conceição (orgs.) Dimensões epistemológicas da pesquisa (auto) biográfica: Tomo I. Natal: EDUFRN; Porto Alegre: EDIPUCRS; Salvador: EDUNEB, 2012. Coleção Pesquisa (Auto) Biográfica: temas transversais.

ESTÉTICA. In: ABBAGNANO, N. Dicionário de filosofia. São Paulo: WMF Martins Fontes, 2014.

FERRAROTTI, F. Sobre a autonomia do método biográfico. In: NÓVOA, A.; FINGER, M. (Orgs.). 0 método (auto)biográfico e a formação. São Paulo: Paulus; Natal: Editora da UFRN, 20I0. p. 2955.

FREIRE, P. Pedagogia do Oprimido. 25. ed. Rio de Janeiro: Paz e Terra, 1998.

GALEANO, E. Livro dos abraços. 27. ed. São Paulo: L\&PM Pocket, 2019.

HOYUELOS, A. A Estética no pensamento e na obra pedagógica de Loris Malaguzzi. São Paulo: Phorte, 2020.

JOSSO, M. Experiência e vida e formação. Trad. José Claudino e Júlia Ferreira. São Paulo: Cortez, 2004.

KRENAK, A. Ideias para adiar o fim do mundo. São Paulo: Companhia das Letras, 2019.

Olhar de professor, Ponta Grossa, v. 24, p. I-18, e-17624.080, 2021.

Disponível em <https://revistas2.uepg.br/index.php/olhardeprofessor> 
As linguagens expressivas e a Pesquisa Narrativa (auto)biográfica: contribuições para a formação docente...

LE BRETON, D. Antropologia dos sentidos. 2. ed. Petrópolis: Vozes, 2020.

MALAGUZZI, L. Ao Contrário, as cem existem. In: EDWARDS, C.;GANDINI,L.;FORMAN, G. As cem linguagens da criança: a abordagem de Reggio Emilia na educação da primeira infância. Trad. Dayse Batista. Porto Alegre: Editora Artes Médicas Sul Ltda., 1999.

MORIN, E. Sobre a Estética. Rio de Janeiro: Pró-saber, 2017.

NASCIMENTO, P. M. F. Arte e formação de professores de educação infantil: um olhar sensível sobre a docência. Niterói, 2019. I44f. Projeto para exame da qualificação. Faculdade de Educação, Universidade Federal Fluminense, Niterói, 2000.

NÓVOA, A. et al. Vidas de professores. 2. ed. Porto: Porto, 1995.

NÓVOA, A. A formação tem que passar por aqui: as histórias de vida no projeto Prosalus. In:

FINGER, M. (Org.) O método (auto)biográfico e a formação. São Paulo: Paulus; Natal: Editora da UFRN, 2010. p. I43-I75.

OSTETTO, L. E. A arte no itinerário da formação de professores: acender coisas por dentro.

Reflexão e Ação, Santa Cruz, v. I4, n. I, p. 29-43, jan./jun. 2006.

OSTETTO, L. E. Fazer à mão para falar de si: a dimensão estética na formação e nas narrativas de professores. In: MONTEIRO, F. A.; NACARATO, A. M.; FONTOURA, H. A. da (Orgs.). Narrativas docentes, memórias e formação. Curitiba: CRV, 2016.

RIBEIRO, T.; SOUZA, R.; SANCHES, C. (Orgs.). Conversa como metodologia de pesquisa: por que não? Rio de Janeiro: Ayvu, 2018.

RINALDI, C. Diálogos com Reggio Emília: escutar, investigar e aprender. Trad. Vânia Cury. São Paulo: Paz e Terra, 2012.

TERRAGROSA, A. Da arte e da narração à sensível textura de nós. In: MARTINS, R.; TOURINHO, I.; SOUZA, E. C. (Orgs.). Pesquisa Narrativa: interfaces entre histórias de vida, arte e educação. Santa Maria: Editora da UFSM, 2017.

VECCHI, V. Estética y aprendizaje. Prólogo. In: HOYUELOS, A. La estética en el pensamiento y obra pedagógica de Loris Malaguzzi. Barcelona: Octaedro; Rosa Sensat, 2006.

VECCHI, V. Arte e criatividade em Reggio Emilia: explorando o papel e a potencialidade do ateliê na educação da primeira infância. Trad. Helena Bonini. São Paulo: Phorte, 2017.

Recebido em: 14 de março de 2021 .

Versão corrigida recebida em: 25 de abril de 2021.

Aceito em: 28 de julho de 2021.

Publicado online em: 03 de setembro de 2021.

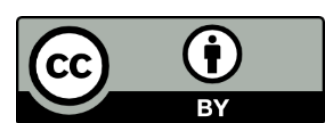

Olhar de professor, Ponta Grossa, v. 24, p. I-18, e-17624.080, 202 I.

Disponível em <https://revistas2.uepg.br/index.php/olhardeprofessor> 